\title{
As transformações da mensagem jornalística dentro do documento sonoro radiofônico, sob o foco da Ciência da Informação: um espaço para o estudo da comunicação extensiva de dados
}

\author{
Clayton W. Nascimento de SALES* \\ Elmira L. M. S. SIMEÃO**
}

\begin{abstract}
Resumo
A partir da compreensão do conceito de comunicação extensiva, é possível entender porque um veículo de comunicação como o rádio, adquire características flexíveis de transmissão da informação, principalmente quando há um armazenamento de conteúdos sonoros em um serviço de internet agregado a uma emissora jornalística.
\end{abstract}

Palavras-chave: Comunicação extensive. Rádio. Comunicação de Massa.

Título: Las transformaciones en el mensaje periodísticos de los documentos sonoros radiofónicos, bajo el enfoque de Ciencias de la Información: un espacio para el estudio de la comunicación extensiva de datos

\section{Resumen}

A partir de la comprensión del concepto de comunicación extensiva, es posible entender por qué un vehículo de comunicación como la radio, adquiere características flexibles de transmisión de información, especialmente cuando hay un almacenamiento de contenido en un sólido servicio de Internet añadido a un periodismo televisivo.

Palabras-clave: Amplia comunicación. Radio. Comunicación de masas.

Title: The changes in message news radio noise within the document, under the focus of Information Science: a space for the study of extensive data communications

\begin{abstract}
Understanding the concept of extensive communication leads to the understanding of why a vehicle of communication such as radio acquires flexible characteristics of transmission of information, especially when there is storage of content in Internet with audio service added to broadcast journalism.
\end{abstract}

Keywords: Extensive communication. Radio. Mass Communication.

\footnotetext{
* Mestre em Ciência da Informação e Professor da UNIDERP.

** Doutora em Ciência da Informação e Professora da UNB.
} 


\section{Introdução}

A informação pode ser definida de várias formas, cada área do conhecimento se apropria do conceito para buscando um sentido apropriado ao universo de pesquisa com o qual se identifica. Dentro da Ciência da Informação isto não é diferente, as transformações ocorridas com a tecnologia tornaram ainda mais imprecisas as definições do termo. Tais mudanças podem configurar de maneira decisiva no próprio modo como a sociedade realiza sua integração e como ela utiliza dessa interação para produzir os meios necessários ao seu registro. $\mathrm{O}$ ato de comunicar é também um permanente aprendizado que se alterna entre a descoberta, a desconstrução e o reaprendizado sobre o ato de comunicar e de utilizar informação.

Por essa razão, estudar os fenômenos informacionais, principalmente aqueles que se caracterizam pelas incertezas proporcionadas pelo advento de novas tecnologias de comunicação, é também uma forma de acompanhar o crescimento e a transformação em parte da vida da sociedade. Neste contexto destacam-se as mídias de massa, como a televisão, os jornais e o rádio, sendo que este último merece atenção especial neste trabalho, por sua permanente acessibilidade, um diferencial que pode ser ressaltado já que está mais próximo dos usuários do que os outros veículos de comunicação. A intimidade criada com seus usuários tornaram o rádio um veículo de massa de linguagem própria e que acompanha as transformações dos artefatos tecnológicos introduzindo-se dentro da rede mundial de comunicação como uma opção de comunicação a mais dentro de um espaço mais interativo e de múltiplas possibilidades.

O rádio enquanto mídia vem sobrevivendo a esses mais de 80 anos de existência no Brasil, com galhardia e diplomacia. Defensor do rádio que classificafa como meio quente, provavelmente Marshall McLuhan não imaginava que seu "tribal drum" ainda serviria de fonte informativa para o mundo, resistindo com segurança e força, às invenções da TV e aos galanteios da internet.

A proliferação de sites noticiosos a partir de matrizes impressas, como os jornais diários, e os serviços próprios inspirados nas agências de notícias também ganharam impulso nos últimos 10 anos. A rede também abrigou a televisão e ampliou ainda mais o poder e o fascínio que exerce sobre a sociedade. A internet cedeu espaço ao rádio, tornando a experiência sonora sentida em amplitudes cada vez maiores. O rádio na internet obriga a 
alterações nos modos de produção da informação e mudanças nas suas formas de divulgação. No entanto, alguns conceitos básicos do jornalismo continuam os mesmos. Resta agora que o rádio busque sua nova identidade, mas para isso é preciso detectar as mudanças de paradigmas que a informação sofre ao ser transferida para o chamado ambiente virtual.

\section{Comunicação extensiva aplicada ao rádio - revisão de literatura}

A partir da compreensão do conceito de comunicação extensiva, é possível entender porque um veículo de comunicação como o rádio, adquire características flexíveis de transmissão da informação, principalmente quando há um armazenamento de conteúdos sonoros em um serviço de internet agregado a uma emissora jornalística. Observadno as transformações ocorridas no ambiente informacional, Miranda e Simeão (2003) afirmam que a comunicação extensiva pode ser definida como um:

\footnotetext{
Sistema aberto, cooperativo e de compartilhamento de dados. Processo com fluxo horizontal que tem como objetivo a solução de um problema que atinge emissores e receptores de conteúdo. É a comunicação sem regras pré-definidas, sem um padrão fixo, sem fronteiras técnicas ou controle que a limite. Há somente uma finalidade a ser cumprida, um desígnio a ser alcançado e instituído. É a interação de emissores e receptores com uma lógica hipertextual, pontual e objetiva em suas metas, mas efêmera, sem estoques e em constante mutação. (2003, p.205)
}

O rádio em si, na qualidade de veículo de comunicação de massas se reveste de características extensivas flagrantes se considerarmos a diferenciação proposta entre a comunicação extensiva e seu antagônico correspondente, a chamada comunicação intensiva. O rádio e a sua convergência para o cyberespaço podem criar novos paradigmas no processo produtivo da informação e determinar novos e mutáveis ritos na comunicação sonora e na recepção auditiva da mensagem radiofônica. A passagem e as possíveis transformações que podem surgir da notícia emanada pelo rádio e a sua versão na internet abrangem modelos que dialogam entre si, proporcionando um compartilhamento de experiências, que podem vir algum dia a determinar a formação de uma nova linguagem.

$\mathrm{O}$ rádio e a internet apelam à informalidade, pois a oralidade de um e a hipertextualidade de outro conduzem a quebras de padrões impostos pelos formatos tradicionais. O rádio e a internet possuem regras flexíveis, afinal tanto um quanto o outro, seguem um cotidiano rodeado de experimentações plásticas e dificilmente padronizáveis. $\mathrm{O}$ rádio e a internet permitem uma leitura expandida, pois a mensagem sonora, embora definida 
por uma linearidade encerrada no tempo e limitada à concentração informativa em um sentido, abre possibilidades interpretativas inigualáveis, pois o poder do imaginário na construção de cenários mentais é o que impõe ao rádio sua razão de ser; por sua vez a internet, com suas redes de interconexões hipertextuais, também expandem o ato da recepção.

O rádio e a internet promovem o inédito, principalmente quando exploram o jornalismo, o rádio por ser praticado sob a premissa do tempo real e a internet pela explosão diuturna de informação e dados. O rádio e a internet apresentam referências diferentes, pois ambas, por não seguirem as mesmas regras, não se incorporam de maneira unívoca à consciência do receptor. $\mathrm{O}$ rádio e a internet proporcionam uma leitura rápida e superficial, já que as dinâmicas de produção de um e do outro levam a modelos de produção fundamentados na quantificação da informação e não na sua qualificação ou depuração. O rádio e a internet atuam em sentidos horizontais, uma vez que ambas, não visam um aprofundamento e sim, uma situação do receptor da mensagem em diversos contextos interconexos da realidade. Feita essa analogia e identificadas as semelhanças de ambos entre si com a comunicação extensiva, é importante reconhecer as diferenças entre os dois ambientes, o sonoro e o virtual.

Determinar uma classificação de um documento é um dos pilares da Ciência da Informação, pois isso integra o rol das prerrogativas basilares da compreensão das diversas abrangências que a informação pode apresentar. Miranda e Simeão (2003, p. 201) propõem uma classificação (figura 1) para compreender a definição de documento e massa documental através de uma célula estrutural. Partindo do pressuposto da complexidade do pensamento estabelecida por Edgar Morin, e do princípio básico da teoria dos sistemas, em que o todo pode ser melhor compreendido conhecendo-se as partes que o compõem e vice-versa, os autores propõem a representação estática dos elementos constitutivos do documento. São eles: tipo, formato, conteúdo e suporte.

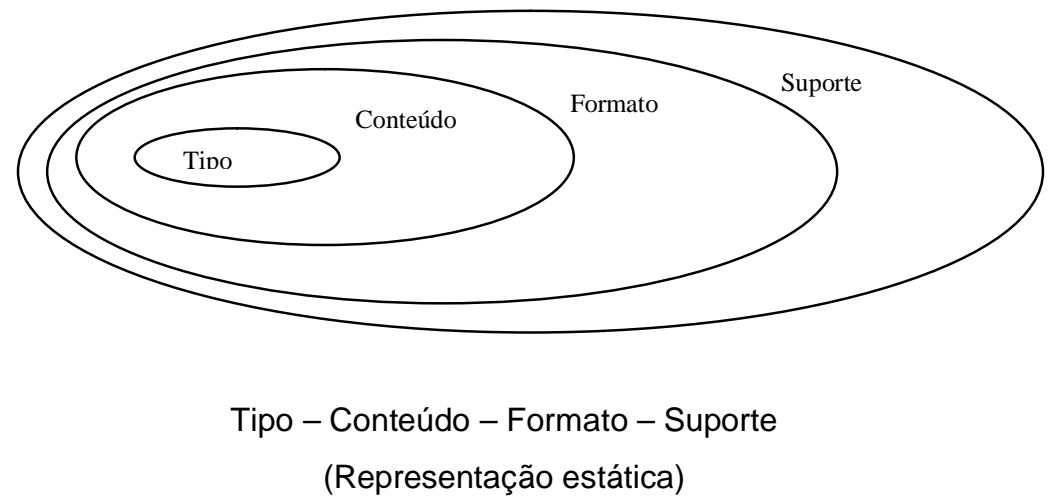

Fonte: Miranda e Simeão, 2003. 
De acordo com Miranda e Simeão (2003, p. 201), o tipo é nomeclatura, a classificação ou o nome que se dá a uma informação (no rádio, por exemplos, destacamos as noticias, manchetes, comentários, etc. O tipo é a base da compreensão do formato e está associado com a sua produção. Eles afirmam que "são formas que, por força de sua reconhecibilidade, predeterminam os modos de produção e uso". O tipo ou tipificação de um documento se refere à maneira com que será trabalhada a produção de conteúdo e o parâmetro central para a elaboração da informação a ser disseminada ao usuário. Ele está na raiz mais central da manufatura dos dados a serem convertidos em conhecimento registrado, já que classificando o documento conforme suas características mais primordiais (indicadas por uma nomenclatura reconhecida) é possível compreender a sua nuances lógicas e seus detalhes intrínsecos.

Um exemplo utilizado pelos autores para ilustrar essa denominação são os artigos científicos, pois representam diversos pressupostos, como as normas para a sua produção e veiculação, e a autoria. Além disso, há o aspecto que não se mantém estático no tempo, uma abertura para modificações em padrões de produção.

Transferindo essa classificação para a mensagem do rádio, é possível determinar parâmetros de classificação documental. Nas características que configuram a tipificação do documento, como a autoria, o enquadramento em normas técnicas é a base para o estabelecimento de uma orientação que ajudará todo um ciclo informacional. Elementos (tipologias) como a reportagem, o boletim, a entrevista, o comentário, o debate e o documentário musical, são o ponto de partida para a produção jornalística, pela qual os profissionais do rádio vão organizar suas informações preliminares através da pauta, roteiro ou script, emoldurando a notícia ou a correlação de várias notícias. Cada emissora possui suas próprias normas de confecção e disseminação que poderão interfirir também na formulação da notícia. As programações obedecem à regras para uso do tempo, quantidade de atores envolvidos, estrutura básica de alternância de elementos internos (dinâmica entre passagens e sonoras, no caso das reportagens e documentários), ritmo de locução, entre outras. Ainda, é sobre essa tipificação do documento sonoro que vai incidir a autoria que, no caso, do jornalismo é representada por créditos e assinaturas.

O conteúdo na visão de Miranda e Simeão é a parte substancial do documento, constituindo a idéia a ser disseminada por um tipo de documento (ou, no caso, por um gênero informativo ou de entretenimento). Essas idéias seguem as regras próprias do tipo escolhido, ou seja, são desenvolvidos em função da classificação (tipificação) estabelecida. Dessa forma, 
voltando ao exemplo do artigo científico, pode-se dizer que o conteúdo é o elemento que "constrói o conhecimento de forma mais dinâmica saindo de uma seqüência linear de percepção, determinando a feitura de novos tipos de documentos" (MIRANDA e SIMEÃO, 2003, p.209). Logo, é possível afirmar que o conteúdo existente nesse tipo de documento, o artigo científico, depende de uma organização interna de dados, a partir de uma metodologia que pode destacar no texto objetivos, justificativas, um corpo teórico, desenvolvimento e uma conclusão expressando um posicionamento do autor diante de um tema de pesquisa.

Novamente, transportando o conceito para o material jornalístico no rádio, a analogia permite afirmar que o conteúdo se exprime inicialmente no ínterim do processo produtivo dos vários tipos de documentos sonoros na forma básica da pauta, que é a determinação muitas vezes metodológica do trabalho produtivo do repórter, com uma definição da abordagem a ser dada ao fato de interesse público. São os assuntos que serão investigados pelo processo de captação das fontes, tratamento e redação textual, edição, adaptação sonora e veiculação.

Outra maneira de compreender o conceito de conteúdo na sua aplicação ao jornalismo radiofônico é a organização de algumas emissoras noticiosas em editorias, o que significa a demarcação dos territórios, do temário geral, que vai conter os tipos de materiais radiojornalísticos, subdivididos nos assuntos discutidos e escalados para aquele dia ou mesmo aquela hora, já que o rádio all news, por exemplo, é um meio que exala jornalismo sem parar um instante sequer. Existe ainda um fator determinante e particular ao documento sonoro radiofônico que é a temporalidade. Tal aspecto possui um grau de relevância determinante no conteúdo, uma vez que a entrevista no rádio, somente para ilustrar, segue uma correlação de fatos e acontecimentos balizados pelas horas e minutos.

O formato diz respeito ao "modo de concepção e exposição do conteúdo". (MIRANDA e SIMEÃO, 2003, p. 204). Isso significa que o formato obedece não a um parâmetro íntimo de regulamentos internos da própria elaboração do documento ou a padrões subjetivados, mas concatenados com o tipo, e sim um conceito básico e mais genérico, que auxilia na moldagem das idéias que serão desenvolvidas. Já que formato remete imediatamente à forma, então essa parte do todo documental incide decisivamente no conteúdo provocando a necessidade de tratamentos diferenciados a partir do instante em que há alterações significativas, uma vez que formato e conteúdo são elementos indissociáveis.

Dentro do universo do radiojornalismo e mesmo do rádio de uma maneira geral, a expressão formato é muito utilizada para expor a idéia de padronização geral com a finalidade de estabelecer um grau razoável de inteligibilidade a um contexto mais geral de uma 
programação radiofônica. Ferraretto (2001, p. 61) define formato como "uma espécie de filosofia de trabalho da emissora, marcando a maneira como ela se posiciona no plano mercadologicamente das idéias". Ele também mostra quais os formatos detectados e praticados nas emissoras de rádio do país, dentro os quais se destacam os formatos híbridos, como os de participação do ouvinte e os programas de música-esporte-notícia, e os chamados puros, como os programas musicais, comunitários, educativo-culturais, místico-religiosos e os informativos ou all news, em que toda a programação é preenchida única e exclusivamente por jornalismo, sem a presença de profissão de fé religiosa, entretenimento, programação musical e interação comunitária. Dessa maneira, é possível afirmar que o formato informativo abrange os conteúdos mais diversos norteados, pelo menos teórica e eticamente, pelo interesse público, que são desenvolvidos sobre os alguns tipos comuns de material radiojornalístico.

Finalmente, o suporte é o conceito mais generalizado de todos os componentes constituintes do documento. É sua a parte visível e manipulável, ou "o documento propriamente dito" (MIRANDA e SIMEÃO, p. 204). Trata-se do aspecto palpável, a manifestação física e concreta do documento, e como o próprio termo deixa entendido, é o que sustenta todas os outros elementos constitutivos do documento. $\mathrm{O}$ artigo científico pode ser colocado à disposição do público sobre o suporte da revista ou periódico científico, ou sobre o suporte do periódico eletrônico. Isso demonstra outra característica do suporte, que é a sua maleabilidade em aceitar o mesmo tipo, conteúdo e formato de documento sobre suportes diferentes. É o elemento mais diretamente relacionado com os avanços tecnológicos. Isso pode provocar alterações no modo de produção, nas definições de formato e na elaboração do conteúdo. Um artigo científico publicado em uma revista impressa, embora possua exatamente o mesmo teor do que o veiculado em um periódico eletrônico, pode sofrer modificações, já que as normatizações técnicas e limitações de espaço, bem como o direcionamento que cada suporte, impresso ou eletrônico, vai adquirir com relação aos diferentes públicos receptores, são agentes potencialmente modificadores da informação contido em um documento.

Por fim, fazendo nova analogia com o documento sonoro, o suporte em questão é o meio de comunicação de massas conhecido como rádio e é sobre ele que se desenrolam as propostas de associação ao modelo de célula estrutural do conhecimento registrado. O rádio como veículo de propagação da informação sonora a ser captado pelos receptores da mensagem pelas vias auditivas é antes de tudo um sistema eletrônico, de propagação em ondas eletromagnéticas, definido por sua capacidade de disseminar o ato comunicativo - ou 
pelo menos, um lado dele - a distâncias longas e abrangentes, limitadas apenas pela capacidade técnica dos transmissores, pelos graus de sofisticação dos aparelhos sintonizados e pelas restrições legais determinadas pelos legisladores oficiais e impostas pelo poder concedente, no caso brasileiro, o executivo federal. Configura-se alteração de suporte, o translado de um debate radiofônico realizado durante 30 minutos ao vivo em uma emissora noticiosa, para uma home page, na qual esse material é armazenado e disponibilizado para futuras consultas por parte dos usuários. Nota-se que, apesar de ser o mesmo material, o mesmo tipo, o mesmo conteúdo, no mesmo formato, é um suporte diferente, pois do rádio como estrada de passagem para a informação, passou-se à internet, outra estrada de passagem para a mensagem.

Recapitulando todas as analogias exercitadas na tentativa de propor uma abordagem melhor detalhada da mensagem sonora enquanto documento a partir da comunicação extensiva, manifesta em termos práticos, pelo modelo dos elementos constitutivos do conhecimento registrado, pode-se concluir que a informação jornalística radiofônica adquire os parâmetros demonstrados no Quadro 1 a seguir:

\begin{tabular}{|c|c|c|}
\hline $\begin{array}{c}\text { ELEMENTO } \\
\text { CONSTITUTIVO }\end{array}$ & DEFINIÇÃO & $\begin{array}{l}\text { REFLEXO NA } \\
\text { RADIOFÔNICA }\end{array}$ \\
\hline $\begin{array}{l}\text { Tipo (Reportagens, } \\
\text { pautas, etc) }\end{array}$ & $\begin{array}{l}\text { Formas de classificar } \\
\text { publicações que divulgam o } \\
\text { conhecimento. }\end{array}$ & $\begin{array}{l}\text { Autoria (créditos e assinaturas), normas } \\
\text { internas de produção, unidade do ciclo } \\
\text { informacional. }\end{array}$ \\
\hline Conteúdo & $\begin{array}{l}\text { Idéias a serem divulgadas } \mathrm{e} \\
\text { gerarem novas idéias. }\end{array}$ & $\begin{array}{l}\text { Temporalidade, processo de pauta, } \\
\text { captação, redação, edição e divulgação. } \\
\text { Implicações éticas. }\end{array}$ \\
\hline Formato & $\begin{array}{l}\text { Arquitetura que determina a } \\
\text { absorção da informação. }\end{array}$ & $\begin{array}{l}\text { Enquadramento no plano das idéias. } \\
\text { Estética e conceito. }\end{array}$ \\
\hline Suporte & $\begin{array}{l}\text { Base física que reúne as } \\
\text { idéias. }\end{array}$ & $\begin{array}{l}\text { Tecnologia, implicações legais } \\
\text { maleabilidade. }\end{array}$ \\
\hline
\end{tabular}

Quadro 1 - Elementos do documento e reflexos na informação no rádio. Fonte: Sales, 2006, baseado em Simeão e Miranda, 2003.

Essas são as bases para se tentar identificar possíveis transformações que a informação radiofônica jornalística sofre ao ser transportada para outra forma de comunicação extensiva que é a internet. 


\section{Metodologia}

Para compreender quais alterações a informação radiofônica jornalística sofre ao ser transportada para o chamado ambiente virtual, foi necessário recorrer à análise de um objeto específico, no caso, a situação em que se encontra atualmente a rádio da Central Brasileira de Notícias $(\mathrm{CBN})$. Por se tratar de uma emissora tradicional no tocante o jornalismo em rádio no Brasil, ela se coloca como pioneira em vários aspectos, como, por exemplo, a inovação de ousar implantar o modelo de radiojornalismo all news - 24 horas de notícias - em uma rádio de freqüência modulada (FM), o que ocorreu em São Paulo, a partir do ano de 1997, sob a coordenação do jornalista Heródoto Barbeiro. Dessa forma, é possível afirmar que as contribuições que a CBN estabelece no radiojornalismo são dignas de referência e reflexão por parte dos profissionais da área.

Dessa maneira, a escolha pelo objeto de estudo se deve a tal importância que a CBN possui para a imprensa nacional e também por possuir um site bem arquitetado em sua

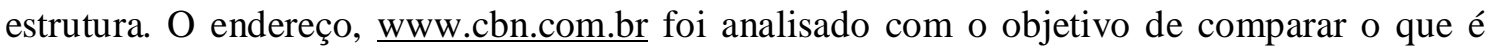
veiculado ao vivo na rádio com o que está armazenado na home page. A meta desse procedimento foi detectar as semelhanças e diferenças no trato da informação nos parâmetros relativos ao suporte utilizado, o tipo estabelecido, formatos praticados e conteúdos disseminados, ou seja, os "elementos constitutivos do documento" (MIRANDA, 2003, p. 203). A comunicação extensiva não contribui apenas como um arcabouço teórico, mas também para a aplicação metodológica com o fim de verificar essa trajetória que a informação radiofônica jornalística percorre até o ciberespaço.

A pesquisa destinada para cumprir com os objetivos determinados é caracterizada como teórica ou básica, que consiste em uma modalidade em que a meta é "conhecer por conhecer. Não há preocupação imediata quanto a seus resultados” (BARROS e LEHFELD, 1988, p. 34). A pesquisa também pode ser classificada como descritiva, pois objetiva a descrição do objeto por meio da observação ou levantamento de dados. A proposta da aplicação dessa metodologia é buscar compreender por quais processos a informação sonora deixa de ser um ente não-palpável, portanto, esvaecido para se transformar em um elemento sustentado pela perenidade da internet.

Então, resumindo, a pesquisa consiste na observação do site da CBN e a audição da emissora ao vivo para o enquadramento no modelo de massa documental, que contém os elementos constitutivos do documento. Essa observação foi realizada durante o período de 
uma semana, entre os dias 27 de março de 2006 a 3 de abril de 2006. Dessa maneira procurou-se detectar o percurso que a informação radiofônica realiza para se adaptar ao ambiente virtual, considerando suas novas práticas de produção.

Dentro dos elementos detectados no objeto de estudos mencionado, foram estudados: as reportagens, os boletins, a entrevistas, os debates e mesas-redondas, os comentários e os documentários musicais.

\section{Análise dos dados a partir da célula estrutural do conhecimento objetivo}

Quanto ao tipo, as reportagens sofreram modificações, uma vez que compreende-se essa tipificação de documento sonoro com um componente integrante de um contexto temporal, logo factual. Uma notícia fez sentido na circunstância e o seu armazenamento no arquivo da emissora serve apenas como peça de referência ou mesmo consulta. A reportagem, portanto, deixou de ter o seu atributo de notícia, pois perdeu sua "validade", já que novas informações foram sobrepostas, reciclando a factualidade. A reportagem deixou de ser reportagem, pois esse tipo de documento sonoro está intimamente ligado ao fator tempo, e se tornou um registro sonoro que um dia, uma hora, alguns minutos e alguns segundos foi uma reportagem. Outra alteração sofrida por esse tipo de material está explícita na própria preparação para a internet. Na veiculação original na emissora, um âncora enunciava uma introdução contextualizadora, que no jargão jornalístico é comumente chamada de "cabeça do apresentador". No ambiente virtual do site, esse papel é exercido pelo título e legendas escritas, o que caracteriza um outro aspecto da convergência midiática, no caso, a convivência com diversas formas de reprodução, como o texto e o áudio. Isso auxilia o ouvinte-usuário a se situar no contexto da notícia, da mesma forma que o apresentador o faz, mas continua padecendo da perda da atualidade, o que leva à obsolescência.

O boletim passa por alterações semelhantes quanto ao tipo, principalmente no que diz respeito aos assuntos ligados a temas de grande repercussão em que opinião do jornalista serve de parâmetro de credibilidade. $\mathrm{O}$ risco da defasagem se torna presente, o que reveste a informação radiofônica da obsolescência. Menos que a reportagem, pelo fato desta não apresentar o elemento interpretativo, contido na prática da análise imediata ou não do fato e suas circunstâncias, causas e conseqüências. Tecnicamente, a mudança no referencial de enunciação prévia também está presente nos boletins da CBN disponibilizados no site. No entanto, às vezes, a presença do âncora no áudio acaba reforçando de forma prolixa, o que foi 
anunciado pelo título e pela legenda.

Já os comentários, quanto ao tipo, passam por mudanças, mas sob um foco diferenciado. Enquanto que as reportagens e boletins são alterados no seu sentido, perdendo a função básica para o qual foram definidos, logo não merecendo mais essas denominações, os comentários mantêm sua atribuição, mas acabam ampliando o caráter consultivo dessa tipificação quando são postados no ambiente virtual. Isso se deve à personalização caracterizada da opinião ou da análise dos comentaristas, na qual o nome que sustenta o crédito desses jornalistas junto à opinião pública ajuda a minimizar o efeito da desatualização. O simples fato de se ouvir um comentarista como Juca Kfouri já é por si só um atrativo.

As entrevistas e debates e mesas-redondas (Fato em Foco), enquanto tipos de documentos sonoros sofrem poucas alterações, já que a ampliação do espectro da notícia para além do fato relatado, auxilia também a reduzir o impacto da transformação em arquivo sonoro disponível na internet. A convivência do jornalista com uma ou mais fontes contribui para inserir o elemento interpretativo, o que ajuda a manter um pouco mais a caracterização original desses tipos radiofônicos. O aprofundamento jornalístico tem se demonstrado um fator atenuante do golpe acusado pelos demais tipos de documentos sonoros anteriormente estudados, como os boletins e as reportagens. No entanto, há a aparentemente inevitável modificação também presente nas entrevistas, debates e mesas-redondas, de inserção dos elementos textual escrito e hipertextual na enunciação ou "chamada" das matérias, mas sem a linearidade própria do rádio ao vivo. Ao contrário das reportagens, em que esse componente descaracteriza o tipo em relação ao meio original, transferindo o papel de âncora para as legendas e títulos, nos outros tipos há um acréscimo reforçador que legitima de forma redundante o lead ou informações basilares para a compreensão da notícia.

Finalmente quanto aos documentários musicais, no que se refere à tipificação, é o único que passa quase incólume pela transferência do rádio para a internet. Sem a prisão do tempo e da factualidade, os especiais musicais já funcionaram como peça de referência mesmo sendo veiculado ao vivo na rádio. Apenas, uma chamada textual anuncia o tema do material radiofônico e de resto, a tipologia sofre menos transformações que os tipos anteriores estudados aqui. A pesquisa e a maior profundidade em tratar das informações sobre os artistas tornam o documentário musical produzido pela $\mathrm{CBN}$ em registro histórico constante, tanto no rádio quanto no site.

Quanto ao conteúdo, ou seja, as idéias a serem divulgadas a partir da tipificação, não foi detectada qualquer modificação aparente. Acontece que tanto o material disseminado pela rádio quanto o mesmo pelo site, propagam a mesma mensagem e transmitem, em princípio, o 
mesmo conhecimento. O que pode causar certa instigação é saber se quando o material é armazenado no servidor da emissora e disponibilizado ao público, ele sofreu algum tipo de edição, geralmente corte ou manipulação de voz. Dos exemplos analisados, nenhum apresentou mudanças de conteúdo, tanto em debates, entrevistas, reportagens, especiais musicais e comentários. O sentido da notícia foi preservado até mesmo porque qualquer alteração que extraísse a fidelidade do que foi veiculado anteriormente pela rádio, poderia implicar em problemas de natureza ética, o que causaria ranhuras na imagem de veículo de comunicação sério que a CBN possui ou tentar passar ao público.

Em relação ao formato, os materiais radiojornalísticos estão sob a regência do conceito genérico de informativo, conforme proposto por Ferraretto (2003). Trata-se de um posicionamento estratégico da emissora no imaginário popular e, por extensão, no mercado publicitário com vistas a angariar receita com a venda espaços. De acordo com a descrição institucional contida no próprio site, a $\mathrm{CBN}$ visa atender a um público definido entre as classes A e B, ou seja, classificada como um perfil de pessoas com maior poder aquisitivo e formação escolar e cultural; também é definido e exposto que esse mesmo perfil de programação, no caso, o formato, está direcionado às pessoas com mais de 30 anos de idade, o que pressupõe um objetivo de atingir homens e mulheres com maior estabilidade financeira e amadurecimento intelectual para a absorção de notícias pelo rádio.

O único material radiofônico disponibilizado em áudio presente no site, que extrapola o formato informativo é o documentário musical. Tomando por base a classificação proposta por Ferraretto, pode-se afirmar que esse tipo de documento sonoro adquire um hibridismo entre os formatos informativo e educativo-cultural, já que além das características narrativas, textuais e estéticas semelhantes aos outros materiais radiofônicos, ele é revestido de uma camada de textura educacional, no sentido da sua suposta contribuição para a formação intelectual e social do ouvinte usuário, e de um tempero cultural, já que trata diretamente de uma pauta advinda da música enquanto forma de arte e manifestação de bens simbólicos que expressam sentimentos, ideologias e impactos sociais. Aliás, é possível afirmar que possivelmente ao ser transportado para o ambiente virtual, ele perde seu caráter informativo e passa a ser gerenciado sob o conceito educativo-cultural. Logo, há uma mudança sensível no formato desse tipo de documento sonoro presente no site.

É no suporte que a informação radiofônica jornalística sofre suas maiores alterações. A mudança de base física é evidente, uma vez que todos os tipos de documento sonoro aqui descritos antes veiculados pelo rádio ao vivo passam para uma nova plataforma. Tudo é transferido para a internet e isso abre possibilidades e limitações. Como vantagens, pode ser 
mencionada a perda da fugacidade, que consiste em uma característica típica do rádio, na verdade, um traço problemático da informação radiofônica, pois leva a uma baixa retenção do conteúdo por parte do ouvinte. A possibilidade de recuperação de um conteúdo que se perdeu no ar com a veiculação pela emissora ao vivo é um ganho proporcionado pela tecnologia do cyberespaço. Há também o desprendimento da temporalidade, o que é bom e ruim ao mesmo tempo. Positivo porque a capacidade de buscar e recuperar um documento sonoro, uma reportagem veiculada há dois meses, por exemplo, é um ótimo serviço que o site proporciona ao usuário de retomar algum ponto perdido e assim dar continuidade à construção do seu entendimento da realidade. $\mathrm{O}$ aspecto negativo é que se perde com a obsolescência. Os documentos sonoros tendem a se tornar peças obsoletas, servindo apenas para a consulta eventual ou complementação de uma informação que acidentalmente não foi escutada ao vivo na emissora. Como a capacidade de armazenamento tem um limite físico nos servidores de rede de computadores das empresas, a tendência é um enxugamento periódico dos documentos sonoros mais antigos.

Uma outra vantagem oferecida pela mudança de suporte que foi observada é a hipertextualidade e a interação com outras mídias, como a fotografia e, principalmente, o texto escrito. A abertura para a ampliação do espectro da notícia da linearidade da mensagem sonora à não-linearidade obtida pelo site possibilita um enriquecimento informativo considerável e com a "liberdade" de manipulação da ordem em que o usuário vai utilizar os arquivos sonoros e outros elementos do ambiente virtual.

Ao ser transferida para a internet, a informação jornalística perde seu elemento mais caracterizador, o aspecto chave que o definia enquanto produto do trabalho radiofônico, que é a simultaneidade. Perde-se a factualidade, perde-se a temporalidade, embora isso seja uma vantagem, perde-se o elo com o espaço e os personagens, no instante em que eles se configuram como tal. Logo, perde-se o sentido radiofônico, o sentido do radiojornalismo. Por conseqüência, boa parte da emoção humana contida na adrenalina dos repórteres e âncoras, esvai-se, para ceder lugar à sobriedade dos catálogos virtuais de registros sonoros, o que significa dizer que a partir da sua conversão em arquivos de MP3, Wave ou WMA, já o coloca no estágio posterior da história, que é o seu estancamento na organização informacional e na qualidade de material referencial a ser buscado, encontrado e consultado. A informação radiofônica jornalística simplesmente deixa de ser radiofônica, deixa de ser rádio e passa a ser apenas áudio, que a correlação de sons concretos e abstratos, de sons verbalizados ou vocalizados, e não-verbalizados, mas sem a carga da instantaneidade, sem a abertura ao chamado "tempo real". 


\section{Conclusão}

As transformações da informação radiofônica jornalística aqui apresentadas apenas demonstram a necessidade premente dos produtores de conteúdo e, principalmente, dos administradores dessas empresas que prestam serviços comunicacionais, passarem a refletir mais detalhadamente sobre os rumos que a mídia vem tomando. Não resta dúvida que o rádio ainda vai permanecer por um bom tempo como um dos media mais primordiais da humanidade. Contudo, também é indiscutível que, após o advento da internet e todas as suas linguagens e implicações, o "tambor tribal" de McLuhan não será mais o mesmo. Como o rádio sempre vocacionou-se como um porta-voz de uma grande multidão em qualquer lugar no mundo e em qualquer ponto da história ocidental, é imperativo que seus caminhos e seus novos itinerários sejam minuciosamente estudados e seus novos efeitos, reflexos ou mesmo mensagens, sejam exaustivamente avaliados. Isso pode ser um elemento contributivo interessante para conhecermos a própria sociedade em toda a sua heterogeneidade.

\section{Referências}

BARROS, Aidil de Jesus Paes de. LEHFELD, Neide Aparecida de Souza. Projeto de Pesquisa: propostas metodológicas. Petrópolis, RJ: Vozes, 2002.

FERRARETTO, Luiz Arthur. O rádio - veículo, a história e a técnica. Porto Alegre: editora Sagra-Luzzato, 2001.

McLUHAN, Marshall. Os meios de comunicação como extensões do homem. Tradução de Décio Pignatari. São Paulo: Cultrix, 1964.

MIRANDA, Antonio; SIMEÃO, E. A conceituação de massa documental e o ciclo de interação entre tecnologia e o registro do conhecimento. DataGramaZero - Revista de Ciência da Informação - v.3 n.4 ago/02. Artigo 03. Disponível em:

<http://www.antoniomiranda.com.br/LivrosPDF/CInformacao/dgzeroartigo.pdf > . Acesso em: [s.d.]. 
MIRANDA, Antonio. SIMEÃO, Elmira (Org). Ciência da Informação: teoria e metodologia de uma área em expansão. Brasília: Thesaurus, 2003. 212 p.

SIMEÃO, E. Comunicação extensiva e informação em rede. Brasília: UnB, Departamento de Ciência da Informação e Documentação, 2006. 